Vol. 12 (1) - Febrero 2018 - http://dx.doi.org/10.21110/19882939.2018.120114

\title{
UN PASEO POR "PALOS EN LAS RUEDAS" Obra de LUIS RAIMUNDO GUERRA CID
}

\section{Realizada por Lorena Parra Méndez ${ }^{1}$}

Me gustaría empezar por la presentación de Luis Raimundo Guerra Cid, normalmente cuando leo el currículum de un autor, me fijo en cuál ha sido su trayectoria, es la mejor forma de saber qué le ha ido interesando. Raimundo se licenció en Psicología y en Antropología Cultural y Social, se doctoró cum laude en Psicología y fue Premio Extraordinario de Investigación por la Universidad de Salamanca. Después de eso amplió aún más su enfoque hacia la medicina, a través del experto en Medicina Psicosomática y psicología de la salud de la Sociedad Española de Medicina Psicosomática y Psicología Médica, sociedad de la que también forma parte; así como de su especialidad en Pedagogía, Medicina Preventiva y Dirección Familiar. En este currículum puede verse muy bien, cómo el autor ha ido ampliando su formación hacia la medicina y hacia la atención a la familia. Discípulo directo del doctor Luis Cencillo de Pineda, actualmente sigue siendo docente de su método, la psicodyalisis, en el máster de Psicoterapia que se imparte en la Universidad de Salamanca.

Ha escrito doce libros y otros tantos artículos científicos, y en los últimos años su práctica y su investigación se han centrado tanto en la neurociencia como en la aplicación de la teoría de sistemas dinámicos no lineales a la psicoterapia desde un enfoque dialytico-relacional, esta aplicación le ha otorgado un puesto en los congresos nacionales e internacionales de IARPP (International Association for Relational Psychoanalysis and Psychotherapy), asociación de la que también forma parte.

Ipsa Levante, el instituto del que es director fue creado en el año 2001 con el objetivo de formar psicoanalistas y actualmente es una referencia en Valencia, por su innovadora oferta formativa y por su organización y participación en diferentes congresos nacionales.

El último libro de Raimundo Guerra tiene este título porque es un libro sobre trauma, sobre aquello que nos puede suceder a cualquiera de nosotros, dificultándonos el camino, y sus consecuencias a largo plazo. Os ofrezco un paseo por el libro, un recorrido por las paradas más interesantes como si de un tour se tratase, vale la pena, y es que sobre trauma se escribe y se escribirá mucho, pero este libro contiene las aportaciones actuales más útiles para

\footnotetext{
${ }^{1}$ Parra Méndez, L. (2018). X. Clínica e Investigación Relacional, 12 (1): 177-183. [ISSN 1988-2939] [Recuperado de www.ceir.info] DOI: 10.21110/19882939.2018.120114
} 
comprender aquello que aún no sabíamos sobre el fenómeno traumático. He mantenido los títulos originales de los capítulos porque me encantan y se que a vosotros os gustarán también. Pasen, y vean.

1. Lo que traumatiza. Este primer capítulo expone tanto los orígenes del estudio del trauma, como aquellos temas que son más relevantes a la hora de entender el fenómeno traumático. En primer lugar, se habla de la preconcepción, se ha escrito mucho sobre trauma, eso hace que todos tengamos en mente qué consecuencias pueden seguir a un hecho traumático o qué hechos pueden resultar traumáticos en sí, el autor nos invita a dejar de lado estas ideas preconcebidas. Conforme avancéis en la lectura, entenderéis el motivo por el que es tan importante no dejarse arrastrar por ellas.

Como no podía ser de otra forma, el contexto se ensalza como un gran moderador de las experiencias difíciles de la vida, convirtiéndose en un elemento esencial a la hora de asumir o disociar dicha experiencia. También nos llamará la atención sobre el hecho mismo de la disociación, no mantener recuerdos de algo, no poder acceder a ellos, no quiere decir que no vayan a tener efectos en nuestra vida.

2. Dónde cicatriza (o no) el trauma: el selfy su dinámica. En este segundo capítulo se pretende aportar una visión amplia del self y de la influencia de lo insoportable, desde lo que no podemos manejar de nosotros mismos, hasta aquello que otros imponen y que dificulta la vida de quienes les rodean. Una insoportabilidad que ya no sólo forma parte del individuo y de su círculo próximo, sino que se ha extendido a una sociedad que cada vez tiende más a lo superficial, el autor dirá de corte sádico-narcisista.

En este contexto Raimundo acabará por preguntarse si podemos tener una identidad sólida. Para tratar de dar respuesta a esto, en el libro se explican tanto el concepto de modernidad sólida, como el de modernidad líquida y se hace una reflexión sobre cómo gestionamos nuestra vida y nuestros tiempos. Siempre tengo la sensación de que las reflexiones de Raimundo fondan, no digo que sean agradables de escuchar, porque tienen ese punto crítico necesario en las personas que tienen algo que decir, pero sí dan perspectiva. $Y$ es que parece poco probable que estemos preparando a las siguientes generaciones en la construcción de una identidad sólida, parece que les estamos enseñando más a subsistir, a sobrevivir, que realmente a vivir con plenitud. Y si en esta ecuación colocamos ya un trauma, en un self que está siempre pendiente de integración y siendo fragmentado de base, su capacidad de manejar el trauma, compartirlo y superarlo puede llegar a verse casi como ciencia ficción.

3. Somos matrioskas. Aquí se va a hablar sobre cómo a veces confundimos el querer conseguir la genuinidad, como objetivo terapéutico, con la perfección, nada hay de perfecto en lo humano, la naturaleza humana es fallida. Tras esta introducción irá desgranando el 
conflicto actual sobre el self, a saber, si es estable y unitario o si es múltiple y discontinuo, aportando la visión de Mitchell, acompañándola de la propia visión del autor a través de su experiencia clínica. La comparación que hace entre la multiplicidad del self en cada uno de nosotros y las matrioskas me parece muy acertada y creo que ayuda a comprender mejor, con este ejemplo tan visual, cómo funciona realmente la integración, pero también aporta una reflexión sobre el sufrimiento que pueden generar, si no están convenientemente "colocadas".

Estoy con el autor en que hoy lo que "vende" y no sólo en psicoterapia, es la rapidez, es el centrarse en lo positivo, en lo bueno, y Raimundo explica que hay personas que no pueden "salvarse a sí mismas", que no pueden salir adelante sin otro que le ayude a ponerse de pie. Pero es que eso implica hacerse cargo de quienes somos realmente, con nuestras luces y nuestras sombras, y hay quien en cuanto empieza a ver sombra, se aterra. $Y$ hay quien se aprovecha de esto, conscientemente o no, para vender un tipo de ideas, como dirá el autor, "si quieres, puedes", con el consiguiente daño para el que se ve no pudiendo, aunque intentándolo con todas sus fuerzas.

Seguramente terminar el tercer capítulo con la reflexión basada en la obra de Orwell 1984, es el mejor fin de fiesta posible. Considerando a la policía del pensamiento como los modernos haters que persiguen diversas causas que odiar y criticar en redes sociales, inicia la reflexión dando entidad a la opinión de los profesionales formados y con experiencia, animándolos a poder expresar lo que piensan pasando por encima de las críticas que esto pueda suscitar.

4. Cómo se traumatiza: la sombra del tsunami. Al hablar de la intersección entre trauma y psicoterapia, una de las primeras ideas que no tarda en emerger es que la psicoterapia no pretende borrar eso que ha sucedido, no puede hacerlo. Pero sí puede ayudarnos, a través de la relación, a conseguir que nuestros recuerdos estén más a mano, a no convertir a la disociación en herramienta constante, porque al final, estamos hechos de lo que hemos vivido, apartar lo que nos ha dañado puede protegernos a corto plazo, pero continua ahí y genera efectos también, sólo que ni los percibimos, ni podemos hacer nada con ellos. La exposición de Bromberg es aclaradora, no sé si estaréis o no de acuerdo conmigo, pero es un autor que a mí me resulta complejo, supongo que porque hablar de la disociación y de cómo funciona una mente que vive bajo esas condiciones tras un trauma, no debe ser sencillo de explicar. Es un autor que cruza siempre sus teorías extraídas de su trabajo clínico con la investigación neurológica, así que sus libros están plagados de referencias como la que da título a uno de los apartados del capítulo cuatro, el detector de humo en este caso sería el sistema límbico. expresa. Este material es para uso científico y profesional exclusivamente y puede contener información clínica sensible. Los editores no se responsabilizan de los contenidos de los autores. Dirigir las consultas sobre derechos y autorizaciones a ceir@psicoterapiarelacional.es 
También se hablará del contexto, de la influencia radical que tiene la respuesta de nuestro entorno ante una situación traumática y lo hace centrándose en dos conceptos de Cencillo que tienen toda la actualidad, por un lado, los envolvimientos cenestésico-afectivos y por otro, el sistema de filtros que resulta de la interacción con nuestras figuras de referencia. El autor realiza el trabajo del trauma desde un enfoque dialytico-relacional, precisamente por esa labor de filtrado, ayudando al paciente, a través de la relación, a poder acercarse a una serie de recuerdos y sensaciones que, sin ese trabajo previo, son realmente problemáticos en el caso de pacientes con trauma grave. El análisis de ese material candente de primera mano, sin la labor del analista, puede y supone una empresa demasiado ambiciosa para el paciente que se siente más seguro y cómodo disociando.

5. Cómo se traumatiza: microtraumas. Iniciamos el siguiente capítulo del libro con la teoría de Margaret Crastnopol a través de la aclaración necesaria de varios conceptos, como son: el trauma acumulativo, el microtrauma y el conflicto intergeneracional.

El autor ha comenzado a enriquecer a la terapia dialytica de Luis Cencillo con las aportaciones de los sistemas dinámicos no lineales y, como no podía ser de otra forma, el efecto mariposa reaparece aquí para dar cuenta de los microtraumas enunciados por Crastnopol. En palabras del autor: "En ocasiones los microtraumas siguen esta misma dinámica: pequeños hechos acaecidos en la infancia de un sujeto, pero con fuerte componente emocional, pueden llevar a largo plazo a que este sufra diversos problemas relacionales y desajustes en la personalidad." Así conecta la teoría de Crastnopol con la teoría de sistemas dinámicos no lineales.

A partir de aquí va a enunciar diferentes ejemplos de microtraumas, modos de hacer de los adultos que pueden trasladan problemas a las vidas de la siguiente generación. Estos ejemplos de microtraumas ayudan a comprender perfectamente cómo la crianza marca de forma difícilmente reversible a la siguiente generación y os serán muy útiles a la hora de comprender a los más jóvenes.

6. Cómo se traumatiza: complejidad y caos. Este es mi capítulo favorito del libro, así que me ha costado no extenderme demasiado. En primer lugar, se considera la ausencia de linealidad en lo humano, esto quiere decir que, ante el mismo fenómeno, diferentes personas van a reaccionar de diferentes maneras, no hay un patrón establecido, sino gran cantidad de variables que influyen en el mismo fenómeno y que son tomadas de manera distinta por quien las experimenta en función de quién es, de cómo ha vivido y de cómo ha aprendido a estar en el mundo. El autor continúa aplicando las ideas de sistemas dinámicos no lineales a la formación del self, que va a ir autoestructurándose durante toda la vida, pero siempre con la gran influencia de las condiciones iniciales. 
En este capítulo confluyen las dos partes, por un lado, la teoría que ha aportado el libro sobre el trauma y por otro los SDNL, se habla del fenómeno de emergencia y del papel de los microtraumas en el colapso de un self, que venía siendo más o menos adaptado hasta ahora. El análisis de la serie "Por trece razones" es el siguiente paso antes de pasar a la retroalimentación de las diferentes variables de alta densidad emocional que convierten al trauma en un asunto complejo. Para acabar, el capítulo se va a centrar en los cambios de la estructura de soporte en la que nos criamos, precisamente porque los traumas pueden suceder en la infancia, pero también a partir de la adolescencia y en la edad adulta. Aquí va a exponer las diferentes variables que entran en interacción y cuyo resultado será incierto en cada caso, ya que cada uno de nosotros tenemos nuestro propio bagaje vital.

Como profesionales, no debemos perder de vista estas variables en el trabajo clínico, y para quienes no se dedican profesionalmente a la psicoterapia psicoanalítica, os pueden permitir comprenderos mejor y comprender mejor el sufrimiento que nos rodea.

7. Lo que le ocurrió a Ana. Se trata de un caso novelado basado en un caso real tratado por Raimundo, tengo que reconocer que mi estómago se cerró al leerlo, trabajo con el dolor humano, pero siempre que leo estas cosas tan crudas, tan asfixiantes, no puedo evitar que se me contagie la desesperación de lo que la paciente tiene disociado. Está muy bien contado, por eso logra transmitir todo esto y después hay un análisis del caso centrado en un sentimiento del que no se habla mucho, pero que es el que más relación tiene con la imagen que tenemos de nosotros, la vergüenza.

8. ¿Quiénes traumatizan? Debido a la influencia y confluencia de diferentes variables en cada uno de los fenómenos analizados, no podemos evaluar qué consecuencias tendrá a largo plazo para cada persona concreta, esto nos da un papel muy directo en el sufrimiento de los demás. Y es que es más probable que nos traumatice quien tenemos al lado, y que nos retraumatice alguien de confianza, puesto que son las figuras a las que solemos pedir ayuda, en quienes ponemos la esperanza de que logren contener lo que nos sucede.

En este capítulo se analiza el papel de los malos conocidos, a saber, psicópatas, pederastas y narcisistas malignos; los desconocidos, como las personalidades adhesivas y el síndrome de Procusto; pero también se habla de la maldad de las personas anónimas, ilustrada en experimentos de psicólogos cuyas conclusiones siempre sorprenden. Finalmente, volviendo a los sistemas dinámicos, haber recibido maldad no predispone necesariamente a devolverla en el futuro, y es que el caos también puede arrojar un rayo de esperanza.

9. Lo que no ayuda: las trampas de la felicidad. Ilustrado por tres confusiones, este capítulo pone en jaque las diferentes formas en que actualmente parecemos perseguir la felicidad, a 
saber, mediante la positividad, buscando la certeza en un mundo incierto y tratando de "ser uno mismo". El autor irá desgranando los diferentes contras, con argumentos sólidos, y es que a veces, seguimos queriendo y creyendo que quien ha tenido dificultades en la constitución de la personalidad va poder llegar a la felicidad inamovible, a través de algunas ideas sueltas, reprimiendo sus emociones, centrándose en el control o imponiendo su santa voluntad a su entorno. Cuando la realidad es que el trabajo necesario para reparar los desajustes de la personalidad no es corto ni fácil.

10. Lo que no ayuda: el refugio y la compensación del amor romántico. Nuestro cerebro relacional nos guía hacia la pareja como un refugio frente a nuestro dolor, sin embargo, las expectativas que se tienen al respecto distan mucho de ser reales. Poder encontrar y mantener la relación de pareja es una inversión de recursos muy grande, en este capítulo se ofrecen diferentes ejemplos de que puede ser "peor el remedio que la enfermedad", como dirá el autor.

11. Lo que no ayuda: de la realidad virtual a la virtualización de la realidad. En este último capítulo se aborda sin tapujos la nueva forma de relacionarnos que implican las redes sociales, y cómo esto está afectando a la capacidad de mentalizar de los humanos, cómo sostiene la imagen de quién necesita narcisistamente ser admirado por los otros mediante un self virtual, en definitiva, cómo se deterioran nuestras relaciones sociales.

La inhibición del mundo en el que vivimos, la desrealización que eso produce es el verdadero problema que ilustra con ejemplos de la serie Black Mirror, haciendo referencia a esa realidad futura que se imaginan y que podría llegar a ser; así como la relación tan superficial que estamos desarrollando con nosotros mismos y con quienes nos rodean.

La capacidad de establecer relaciones y de leer las emociones propias y las de los otros se sostienen en las relaciones cara a cara, la tecnologización de las relaciones tiene consecuencias en la capacidad de mentalizar, genera dificultades en las relaciones y desdobla la imagen que tenemos de nosotros mismos. En el libro podréis encontrar las características que se encuentran en los pacientes que emergen de esa virtualización de la realidad, podemos decir, de los pacientes que nos esperan.

Para finalizar se exponen y explican las bases sobre las que construir una terapia eficaz en pacientes aquejados de estas problemáticas asociadas a la virtualización de la realidad. El autor nos invita a ser críticos con los efectos de la cultura y de la tecnología en nuestra propia vida y en la de la sociedad en la que vivimos, a no conformarnos simplemente o dar por hecho que todo son ventajas en la evolución en la que estamos inmersos. expresa. Este material es para uso científico y profesional exclusivamente y puede contener información clínica sensible. Los editores no se responsabilizan de los contenidos de los autores. Dirigir las consultas sobre derechos y autorizaciones a ceir@psicoterapiarelacional.es 
Epílogo para pesimistas. Entendiendo el pesimismo como una forma de ver lo negativo en lo que nos rodea y que eso nos permita ser críticos, el autor nos invita en este epílogo final a estar más pendientes del sufrimiento que nos rodea, a ayudar a construir y a construirnos, a potenciar nuestra propia identidad genuina, como una forma de comprender el sentido de nuestra vida.

No quiero terminar esta recesión sin dar las gracias a Raimundo por permitirme leer su libro, por darme la oportunidad de escribir sobre él, de invitaros a leerlo, a sumergiros en la mente de un trabajador incansable, que deja parte de sí en todo lo que escribe. Se que este libro os ayudará a comprender mejor vuestro sufrimiento y el de los otros, se que será un antes y un después, porque lo ha sido para mí. Os deseo, de corazón, que los disfrutéis. 